\title{
Relationship between Attitude toward Mathematics and Metacognitive Strategy in Completing Math Word Problem among 3rd Elementary Student
}

\author{
Ariyati ${ }^{1}$, Lucia R. M. Royanto ${ }^{2 *}$ \\ ${ }^{1,2}$ Faculty of Psychology, Universitas Indonesia, Depok, Indonesia \\ *E-mail: lucia.retno@ui.ac.id
}

\begin{abstract}
Mathematical achievement of the students in Indonesia is low and it can be seen in PISA and TIMSS. Mathematics is one of the subjects that require higher order thinking skills, such as metacognition. This research was conducted to find out the correlation between attitudes toward mathematics and metacognitive strategies in completing mathematics word problems among 3rd elementary students. The measurement of attitudes toward mathematics was using adapted Mathematics and Me Survey (M \& MS). The think-aloud method using to measure students metacognitive strategies. Respondents were obtained from two Depok Primary Schools with 89 respondents with an age range of 8 to 10 years. The results showed a positive significant relationship between attitudes toward mathematics and metacognitive strategies $(r=0.229, p$ $<0.05$, one-tailed). From that result, it can be concluded that the more positive the students' attitudes toward mathematics, the more metacognitive strategies used in solving math word problems.
\end{abstract}

Keywords: attitude toward mathematics; metacognitive strategies; mathematics word problem; concrete operational

\section{Introduction}

Mathematics is one of the subjects that become a problem for students, not only in elementary school students but also in high school and college students. Mathematics is still in the first rank subject feared by students. However, the students also receive pressures, not only from parents but also from teachers. It contributes to the students dislike math.

Indonesia students ranked the second lowest in PISA ranking (rank 64 of the 65 countries, participated in PISA 2012) (OECD, 2014). The rating had declined from PISA 2009 which ranked 57 of the 65 participating countries (OECD, 2010). The TIMSS result showed similarities, Indonesian students' math skills were rank 44 out of 49 participating countries by 2015 (Mullis, Martin, Foy, \& Hooper, 2016). The results of PISA and TIMSS showed that Indonesia is still in the lower rank.

Mathematics is needed in everyday life, not only in schools but also in almost all aspects of human life. Mathematics can also be applied by children and also by adults in everyday life. Perna and Loughan
(2014) describe several factors that cause math less favored, one of the contributing factors is the complex mathematical nature. Mathematics has a high level of difficulty, especially for those who do not like it. Another factor it is that makes students hate math because regarded as unfamiliar (Fuentes, 1998; Perna \& Loughan, 2014).

In math word problem, stages are needed, firstly the student must understand the information provided, secondly, they must understand and determine the goals, and lastly determine the operations that must be executed to achieve those goals (Gredler, 2001). In solving this math problem there are some challenging difficulties such as is the difficulty in determining the keywords in the matter, especially about the math word problems (Sajadi, Amiripour, \& Rostamy-Malkhalifeh, 2013). The difficulty in determining these keywords is also influenced by the understanding of individual's reading ability. Only then can the individual construct the situation or context of the matter accurately (Byrnes, 2001). 
Cognitive skills and abilities are indispensable in solving math problems (Perna \& Loughan, 2014). According to Desoete (2008), metacognition is required in doing math problem solving to predict, plan, monitor, and evaluate. In addition, metacognition strategies that play a role in monitoring the cognitive processes that occur are also needed to achieve the intended goal (Flavel in $\mathrm{Du}$ Toit, 2009). This complicated cognitive and metacognitive process has also been one of the causes of the dreaded mathematical subjects.

Students who have difficulty and dislike math lessons will have difficulties. Mathematics achievement is related to attitudes toward positive mathematics (Kuncoroningsih, 2013; Lastuti, 2013). Susanti (2013) describes several factors that influence the success of students in mathematics subjects are internal factors and external factors. Internal factors include motivation, attitude, interests, talents, etc .; While external factors can come from student environments such as teachers, parents, or peers. One of the internal factors of students that can not be separated is the attitude of students to mathematics itself (Susanti, 2013).

There is little research that links attitudes toward mathematics with the important aspects used in solving the math problem itself, namely metacognition. In addition, research that has been done there is a contradiction. There are results of research that explain that attitudes toward mathematics are related to metacognition (Lastuti, 2013), there are also research results that show no relationship (Ajisuksmo \& Saputri, 2017). With the existence of pre-existing research, researchers have hypothesized that attitudes toward mathematics are related to metacognition strategies.

\section{Metacognition}

Flavell (1979) defines metacognition as knowledge and cognition about one's cognitive phenomena. Furthermore, Flavell explains that metacognition strategies as conscious monitoring of individual cognitive strategies to achieve certain specific goals (in Du Toit, 2009). Next will be presented on metacognition components based on metacognition definitions from Flavell (1979). According to Flavell (1979), metacognition component consists of two components: metacognitive knowledge and metacognition experience. Then developed by Efklides (2008) which suggests metacognition consists of 3 components of metacognitive knowledge, metacognition experience, and metacognition skills. The metacognition skill component added by Efklides when further examined is part of Metacognitive strategy according to Flavel and included in the Flavel metacognitive knowledge component.

Metacognitive knowledge is a segment of an individual or a person who stores knowledge of the world as it relates to humans as a cognitive being and with a diversity of cognitive tasks, objectives, actions, and experiences. Metacognitive knowledge consists of 3 categories, namely person, task, and strategy. Metacognitive experiences refer to any cognitive experience or consciousness that accompanies and relates to any intellectual activity. Metacognitive experience can be the short or long duration and simple or complex content. This experience can happen anytime; Before, after or during cognitive activity (Flavell, 1979). Metacognition skills that refer to the use of strategies to control cognition or also called executive control (Efklides, 2008). In addition, metacognition skills can also be defined as actions or strategies that refer to other cognitions or behaviors performed to achieve that goal. Metacognition skills utilize tasks (goals or task) to work.

In this research, which will be seen is metacognition strategy which is a person's ability to monitor consciously against his cognitive strategy to achieve certain goals (Flavell, in Du Toit, 2009; Efklides, 2008). According to Desoete (2008), in metacognition strategy, there are four skills that are a prediction, planning, monitoring, and evaluation.

There are several factors that influence metacognition including the following: environment (Carr, Kurtz, Schneider, Turner, and Borkowski, 1989); Affect (Efklides, 2006; Nader-Grosbois, 2014); Social factors (Karabenick, 1996); Age (Veenman, Wilhelm, \& Beishuizen, 2004; NaderGrosbois, 2014); Intellectual ability (Veenman, Wilhelm, \& Beishuizen, 2004; Nader-Grosbois, 2014).

This study uses metacognition measurement techniques think-aloud protocols used by Montague and Applegate (1993). In this technique, participants will verbalize their cognitive and metacognitive processes during their math problems. Next will produce verbatim which will be coding to the cognitive and cognitive processes that arise during the participants do math problems so that the results can be done the analysis. Measurement, there are 7 cognitive processes and 3 metacognitive activities measured. The process is needed to solve the problem well especially in the context of mathematics. 


\section{Attitude toward Math}

The definition of attitudes toward mathematics refers to self-perception as a mathematics learner who has the belief that having the ability to learn and be capable of performing well and is happy in doing and learning mathematics (Adelson \& McCoach, 2011). Components of attitudes toward mathematics consist of Mathematical self-perception and Enjoyment of mathematics (Adelson \& McCoach, 2011) Factors affecting attitudes toward mathematics are internal factors including motivation (Mata, Monteiro \& Peixoto, 2012) and age (Vella, 2011). External factors such as teachers' expectation of students' mathematics competence also greatly influenced attitudes toward students' mathematics (Gunderson, Ramirez, Levine \& Beilock, 2012; Limpo, Oetomo, \& Suprapto, 2013), peers (Limpo, Oetomo, \& Suprapto, 2013), Anxiety and parental attitudes (Soni \& Kumari, 2017). Parent expectations on the mathematical competence of children (Gunderson, Ramirez, Levine \& Beilock, 2012).

In this study, measurements of attitudes toward mathematics use adaptation of Math and Me Survey (M \& MS) measurements from Adelson and McCoach (2011). Researchers choose this measuring instrument because the measuring tool is still the latest, participants in the development of this measuring tool in accordance with the respondents of this research is the grade $3 \mathrm{SD}$ to grade $6 \mathrm{SD}$. Other than that the number of items is small and the language used is simply adjusting to the respondent.

\section{Methods}

Sample. Research participants consist of 89 elementary students in Depok City. School origin of participants from SD Pemuda Bangsa and SDN Beji Timur 01. Characteristics of participants are students of the $3^{\text {rd }}$ elementary school in Depok City with age range 8 to $10^{\text {th }}$, this range age included the participants in concrete operational of the development stage, participants have a minimum average level of intelligence based on CPM. The sampling method used accidental sampling, based on availability and facility sample access. Recruitment process the sample begins with require permission to schools that will be used for data retrieval. And then researchers ask permission to the parents by providing informed consent. Finally, researchers will take data from participants by adjusting the schedule provided by the school.

Research Design. This type of research is in the form of correlational research that aims to determine the relationship between variables (Gravetter \& Forzano, 2012).

\section{Instrument and Measurement.}

\section{a. Technique of Think aloud}

The technique of thinking aloud used for measuring metacognitive strategy (Desoete, 2008; Jacobse \& Harskamp, 2012). Participants were asked to speak their thinking process during completing math word problem was given. The result of this measurement is verbatim, then analyzed using the coding and scoring framework used by Montague and Applegate (1993). (see table 2.1). Scores obtained from metacognition strategy measurement then correlated with attitude toward mathematics score

Math word problems designed to bring out metacognitive strategy use. Level of difficulties with math word problems designed more difficult more than students learning competence (one level above). Two math word problems are chosen from six math word problem. Six math word problems have been through the stage of expert judgment, then tested against students of grade $3^{\text {rd }}$ elementary school. Then re-analyzed before being used in data retrieval, with some improvements.

Table 2.1

Categories, Code, Operational Definition of metacognitive processes

\begin{tabular}{ccc}
\hline Categories & Code & Operational Definition \\
\hline Hypothesizing & $\mathrm{H}$ & $\begin{array}{c}\text { Designing plans, determining } \\
\text { the order of workmanship, } \\
\text { designing the calculation } \\
\text { operations to use }\end{array}$ \\
Estimating & E & $\begin{array}{c}\text { Predicting answers, comparing } \\
\text { answers with previous ideas }\end{array}$
\end{tabular}

\section{Checking}

Process $\quad \mathrm{CH} 1 \quad$ Check all steps completed or

checking

Product

checking

Attention

control

Self-

correction

Evaluating EV Making judgment, assessing a process

Confirming CO Confirm answers, processes, answers, or problem solving

Self- SE Evaluates itself as a "problem

evaluation solver", using the "I" statement that refers to the performance performed 


\section{b. Attitude toward mathematics measurement}

The instrument for measuring attitudes toward mathematics is a tool developed by researchers based on Math and Me Survey (M \& MS) from Adelson and McCoach (2011). This measurement uses four Likert scales of 1: strongly disagree, 2: disagree, 3: agree, and 4: strongly agree. The higher the M \& MS score indicates that the attitude toward the mathematics of students is getting more positive, and vice versa. $M$ \& MS measures attitudes toward mathematics with 2 subscales of mathematical selfperception and enjoyment of mathematics. The process of adaptation of M \& MS measuring tools conducted by the researchers produced 18 items that are ready to be tested legibility. After the legibility test, the researchers developed a measuring tool that will be used for the tryout. The measuring tool used for the trial amounted to 18 items with a choice of 4 Likert scale response of 1: strongly disagree, 2: disagree, 3: agree, and 4: strongly agree. Participants in the trial amounted to 59 students, divided into 30 from SD Beji Timur 03 and 29 from SD Pemuda Bangsa.

Based on the data at the trial stage of a number of 36 people, then performed calculations of reliability with Cronbach's Alpha technique in SPSS. According to Nunnally and Bernstein (1994), the limit of good reliability coefficients for research is 0.7 . The result of the calculation of the reliability coefficient of the initial $M$ \& MS measuring instrument is $\alpha=.632$. After eliminating the 4 items then the coefficient of reliability increased to $\alpha=$ .769. Thus it can be concluded that the measuring tool attitudes toward mathematics adapted from M \& MS has a good internal consistency because of the reliability coefficient of measuring instrument more than 0.7 which is a good reliability coefficient bounds according to Nunnally and Bernstein (1994). In addition, validity measurements were made using internal consistency against 18 selected items. Based on internal consistency calculations using corrected item-total correlation of 14 selected items, corrected item-total correlation value of 12 items above 0.2 as a good internal consistency limit (Aiken \& GrothMarnat, 2006). However there are 2 items that have corrected item-total correlation value below 0.2 ie items 10 and 11 (item $10=0.08$ and item $11=0.22$ ). Both items are maintained on the basis of both items representing the component of cognition attitudes on the enjoyment of mathematics scale.

\section{c. The Colored Progressive Matrices (CPM) intelligence test}

In this study using intelligence test research instruments using Colored Progressive Matrices (CPM). CPM is divided into three sets namely set A, set $\mathrm{Ab}$, and set $\mathrm{B}$, each of which consists of 12 items that must be answered by the respondents. CPM is designed to assess respondents' intellectual processes. The colored backgrounds on the items are designed to attract attention and make interesting tests and reduce excessive verbal instruction (McCallum, 2003). IQ score is derived from the sum of the correct item scores. The score is then checked by the group using the norm of CPM measuring instrument. The classification of IQ level according to CPM is divided into five, namely class I (superior), class II (above average), class III (average), group IV (below average), and class V (intellectual defective). In this study, respondents who entered into classes I, II, and III who became respondents in the study to measure metacognitive strategies with the assumption that individuals with an average IQ level and/or upwards can use metacognition better.

Procedure. This research begins by determining the phenomenon as the background of the study. After establishing the phenomenon, a literature study of the research variables and the context used. The literature study is done by reading books, journal articles, and news articles on research topics. That, the researchers studied the measuring tool used to measure the variables that have been done that is measurement metacognition strategy and attitude toward mathematics. Measurement of strategy is done by think aloud protocol technique with reference to Montague and Applegate (1993) for coding on verbatim of qualitative data retrieval. Meanwhile, on the measurement of attitude variables on mathematics using Math and Me Scale (M \& MS) measurements developed by Adelson and McCoach (2011) and then adopted by researchers. This M \& MS measure consists of 14 with 4 Likert scales. After determining the measuring instruments and instruments then performed the legibility test and then make improvements from the test legibility test results. After the instrument is improved then the next try out and go to the stage of research implementation.

Retrieval, researchers do it together with group research. Before taking the data, firstly make the process of permission to the school and ask the consent of the guardian using informed consent. After obtaining permission to perform data retrieval 
is done data retrieval. Schools that are used as research samples are SDN Beji Timur 01 and SD Pemuda Bangsa. Data collection was done on group data collection (intelligence test and attitude measurement toward mathematics) and individual (metacognition measurement with think-aloud technique). Measurement of intelligence using CPM. Then the data obtained were analyzed using SPSS. Statistical analysis is done: descriptive statistics; Statistical analysis Pearson Product Moment Correlation; Cronbach's Alpha; Item-Total Statistics; Independent Sample t-test; Analysis of Variance (ANOVA)

\section{Results}

Research problem to be answered in this research is "Is there a correlation between attitudes toward mathematics and the use of metacognition strategies in solving math word problems in grade 3 elementary school students?". Based on the research problem, Alternative Hypothesis ( $\mathrm{Ha}$ ) proposed is a relationship between attitudes toward mathematics and the use of metacognition strategies in solving the math word problems in 3rd elementary students.

The number of respondents in this research is 89 respondents with general picture: (See table 3.1.)

Tabel 3.1.

General description of research respondents

\begin{tabular}{llll}
\hline \multicolumn{2}{l}{ Demographics Aspect } & Frequency & Percentage \\
\hline Gender & Male & 43 & $48,3 \%$ \\
& Female & 46 & $51,7 \%$ \\
Age & 8 years & 22 & $24,7 \%$ \\
& 9 years & 62 & $69,7 \%$ \\
& 10 years & 5 & $5,6 \%$ \\
Group IQ & I (superior) & 51 & $57,3 \%$ \\
& II (above) & 27 & $30,3 \%$ \\
& III (average) & 11 & $12,4 \%$ \\
The origin & SDN Beji & 37 & $41,6 \%$ \\
of school & Timur 01 & & \\
& SD Pemuda & 52 & $58,4 \%$ \\
& Bangsa & & \\
\hline
\end{tabular}

An overview of attitude variable variables on mathematics shows that the minimum score of attitudes toward mathematics is 33 and the maximum score is 56 . With an average score of $46.56(\mathrm{SD}=5,132)$. Then enlist also group the score of attitudes toward mathematics into groups of low, medium, and high. The grouping is done by a hypothetical mean method, that is by looking at all possible scores that can be obtained by the respondent, then divide it into three groups (low, medium, high). Based on the calculation obtained the result that respondents classified as having a high attitude toward mathematics score $(\mathrm{N}=67)$. The general description of metacognition strategy variables indicates that the minimum metacognition strategy score is 7 and the maximum score is 96 with an average score of 31.97 (SD = 21.797). Metacognition process which is included in metacognition strategy which most arises during solving the math word problem is hypothesizing or planning with the frequency of occurrence equal to $2440(75,12 \%)$.

The main results of the study showed that there was a positive relationship between attitudes toward mathematics and metacognition strategies. The increasing score of attitudes toward mathematics is followed by an increase in metacognition strategy scores. It can be concluded that there is a significant positive relationship between attitudes toward mathematics and metacognition strategy in solving math word problems in grade 3 students of elementary school $(r=0,229, n=89, p<0,05)$.

Table 4.2.

The result of correlation of attitude variable to mathematics and metacognition strategy

\begin{tabular}{lllc}
\hline Variable & R & Sig & $r^{2}$ \\
\hline $\begin{array}{l}\text { Attitudes towards mathematics } \\
\text { and metacognition strategies }\end{array}$ & $0,229 *$ & 0.016 & 0,052 \\
\hline * Significant on L.o.S 0.05 (one-tailed) & & \\
\hline
\end{tabular}

\section{Discussion \& Conclusion}

Discussion. The results obtained in line with research conducted by Ozsoy, Memis, and Temur (2009), explaining that metacognition and attitudes have a significant relationship with students with high achievement. This research is in line with research that has been done by Ozsoy, Memis, and Temur (2009).

More on the main results of the study indicating that there is a relationship between attitudes toward mathematics and the use of metacognition strategies. Researchers assume that there are other factors that also explain attitudes toward mathematics. Some studies show several factors that contribute to attitudes toward mathematics, including the classroom environment and parents. Limpo, Oetomo, and Suprapto (2013) explain that attitudes toward mathematics are influenced by the classroom environment, which consists of teachers and peers. This is also supported by the opinion of Allen and Marotz (2010) on the development of children's concrete operating phase that develops closeness with others, including peers. 
In addition to the above factors, there are factors that contribute to the attitude of mathematics. Research by Gunderson, Ramirez, Levine, \& Beilock, (2012), explains that parents and teacher expectations also have an influence on students' attitudes toward mathematics. This is supported by Allen and Marotz (2010) who argue that students in the development stage of concrete operations are still difficult in the face of frustrating conditions and failures. Allen and Marotz (2010) also argue that children at this concrete stage of operation are easily given up in the face of difficult tasks, in which case math is included in fairly difficult subjects. Soni and Kumari (2017) also explained that anxiety and attitudes possessed by parents also play a role in attitudes toward mathematics owned by his son.

Metacognition strategy measured in this study using the technique of think aloud less visible during work on mathematics word problems. The most emerging strategy is hypothesizing, the strategy in preparing the completion plan in the work of math word problems. This is in accordance with the opinion of Allen and Marotz (2010) that the child in the stage of development of concrete operations has developed the ability of planning. But in fact, some students have to give up because they find it difficult in doing math word problem. This is also a consideration in developing the instrument math problem. Mathematics problems that are arranged are made with difficulty levels that are more difficult than the competencies expected of the students but can still be done. Problems designed with a level of difficulty over this competency will require respondents to use metacognitive strategies. The problem is not the same perceived by all respondents, some are able to do but some respondents feel very difficult. This is likely because students have a different understanding of mathematics.

In addition, other factors that influence the emergence of metacognition strategy is the method of think aloud that is still less familiar to the respondents. Respondents still have to be reminded often to keep saying the process of thinking during working on the math word problem given. So in the next research need to provide time to teach the respondents about the technique

Based on the strategy skills delivered by Efklides (2008), which explains that metacognition strategies include prediction, planning, monitoring and evaluation skills. Broadly speaking, the research respondents have been able to apply prediction and planning skills. Respondents are able to predict whether the given problem is difficult or not. Respondents were able to plan what mathematics operations would be used in working on the problem. However, supervision and evaluation skills are still less visible. Respondents are still unable to fully supervise their work whether it is in accordance with the plan, whether the action that he did was appropriate to achieve the objectives according to plan. Respondents also still can not evaluate effectively. When the respondent has finished working on the problem they only evaluate the questions that have been answered but have not been able to evaluate whether the answer he has been appropriate or not. They are still focused on solving the missed problem.

Research conducted by Sajadi, Amiripour, and Rostamy-Malkhalifeh (2013). Shows that students will find it difficult to work on math word problems. This is because the child is still difficult in representing words into a mathematics symbol which can then be performed mathematics operations. Although students have been able to understand the words and numbers, when faced with the word problems, they face difficulties. In addition, the understanding of the language owned by respondents is also very influential on the completion of math word problems given. If the child is unable to construct the problem accurately then it will not be able to solve the problem accurately (Byrnes, 2001). From a mathematical point of view, it is not only numeracy that is required, but also the ability to read problems and turn them into mathematical symbols and complete mathematics operations (Sajadi, Amiripour, \& Rostamy-Malkhalifeh, 2013). In addition, according to Sajadi, Amiripour, and Rostamy-Malkhalifeh (2013), children are also still difficult to choose keywords that exist in the matter of the story. It is a complex process for the 3 rd graders that they find it difficult. The lack of knowledge about mathematics operations and the context used also influences the difficulties in choosing the appropriate mathematics solution strategy, where mathematics solution to the more difficult math problem questions requires metacognition strategies to solve them.

Conclusions. Results show that there is a positive significant relationship between attitudes toward mathematics and metacognition strategy in solving math word problems in $3^{\text {rd }}$ elementary students. The positive relationship means if attitude toward mathematics high (positive), then the metacognitive strategy is high too.

\section{References}

Adelson, J. L. \& McCoach, D. B. (2011). Developmental and psychometric properties of the math and me survey: Measuring third through sixth graders' attitude toward mathematics. Measurement and Evaluation in Counseling 
and Development. 44 (4). 225-247. DOI: $10.1177 / 0748175611418522$

Aiken, L. R., \& Groth-Marnat, G. (2006). Psychological Testing and Assessment. Boston, IL: Pearson Education Group.

Ajisuksmo, C. R. P., \& Saputri, G. R. (2017). The Influence of Attitudes towards Mathematics, and Metacognitive Awareness on Mathematics Achievements. Creative Education, 8, 486-497. Retrieved from http://file.scirp.org/Html/14-6303423_75168.htm

Allen, K. E \& Marotz, L. R. (2010). Developmental Profile: Pre-Birth through Twelve, 6 Ed. Canada: Wadsworth

Byrnes, J. P. (2001). Cognitive Development and Learning: An Instructional Contexts. 2nd Ed. USA: Allyn \& Bacon

Carr, M., Kurtz, B. E., Schneider, W., Turner, L.A., \& Borkowski, J. G. (1989). Strategy Acquisition and Transfer Among American and German Children: Environmental Influences on Metacognitive Development. Developmental Psychology. Vol. 25 No. 5. 0012-1649/89/\$00.75

Desoete, A. (2008). Multi-method assessment of metacognitive skills in elementary school children: how you test is what you get. Metacognition and Learning, 3:189-206. DOI: 10.1007/s11409-008-9026-0

Du Toit, S. \&Kotze, G. (2009). Metacognitive strategies in teaching and learning of mathematics. Journal of the Association for Mathematics Education on South Africa. doi:10.4102/pythagoras.v0i70.39. http://www.pythagoras.org.za/index.php/pythagoras/articl e/viewFile/39/30

Efklides, A. (2006). Metacognition and affect: What can metacognitive experience tell us about the learning process?. Educational Research Review. Doi:10.1016/j.edurev.2005.11.001

Efklides, A. (2008). Metacognition: Defining its facets and levels of functioning in relation to self-regulation and coregulation. European Psychologist. Vol. 13(4):277287. DOI: $10.1027 / 1016-9040.13 .4 .277$

Flavell, J. H.. (1979). Metacognition and Cognitive Monitoring:A new area of cognitive-developmental inquiry. American Psychological Association. Vol.34, No.10,906-911. Doi: 0003-066X/79/3410-0906\$00.75

Fuentes, P. (1998). Reading Comprehension in Mathematics. The Clearing House, Vol. 72, No. 2

Gravetter, F.J. \& Forzao, L.B. (2012). Research Methods for the Behavioral Science 4ed. USA: Wadsworth

Gredler, M. E. (2001). Learning and Instruction: Theory Into Practice. NJ: Prentice-Hall

Gunderson, E. A., Ramirez, G., Levine, S. C., \& Beilock, S. L. (2012). The role of parents and teachers in the development of gender-related math attitudes. Sex Roles, 66(3), 153-166. DOI: 10.1007/s11199-011-9996-2

Karabenick, S. A. (1996). Social influences on metacognition: Effects of colearner questioning on comprehension monitoring. Journal of Educational Psychology. Vol.88 No.4 0022-0663/967S3.00

Kiddienglish.wordpress.com . (n.d). Mengapa matematika menjadi pelajaran yang paling ditakuti siswa?. https://kiddienglish.wordpress.com/mengapa-matematikamenjadi-pelajaran-yang-paling-ditakuti-siswa/

Kuncoroningsih, E. (2013). Hubungan atara sikap siswa dalam pembelajaran matematika dengan prestasi belajar pada siswa kelas VIII SMP Negeri 2 Pabelan tahun ajaran 2012/2013.http://repository.uksw.edu/bitstream/12345678 9/3634/1/T1_202009071_Abstract.pdf

Lastuti, P.(2013). Hubungan antara Sikap Siswa terhadap Pembelajara Matematika dan Kemampuan Metakognisi dengan Hasil Belajar Matematika pada Siswa Kelas VII Madrasah Tsanawiyah Negeri 2 Kudus.

Limpo, J. N. Oetomo, H. \& Suprapto, M. H. (2013). Pengaruh Lingkungan Kelas terhadap Sikap Siswa Untuk Pelajaran Matematika. Humanitas. Vol. X No.1

Mata, M. L., Monteiro, V., \& Peixoto, F. (2012). Attitude toward mathematics: Effects of individual, motivational, and social support factors. Child Development Research. Vol. 2012. http://dx.doi.org/10.1155/2012/876028

McCallum, R, S, (2003). Handbook of nonverbal assessment. NY: Springer. DOI 10.1007/978-1-4615-0153-4

Mindtalk.com. (n.d). Mata pelajaran yang paling ingin dihindari waktu sekolah dulu. https://www.mindtalk.com/channel/orangindonesia/post/ mata-pelajaran-yang-paling-ingin-dihindari-waktu-s53467 4290054796265.html

Montague, M. \& Applegate, B. (1993). Middle school students' mathematical problem solving: An analysis of think-aloud protocols. Vol. 16

Mullis, I. V., Martin, M. O., Foy, P., \& Hooper, M. (2016). TIMSS Advanced 2015 International Results in Advanced Mathematics and Physical. Retrieved from Boston College, TIMSS \& PIRLS International Study Center. Website http://timssandpirls.bc.edu/timss2015/internati onal-results/advanced/

Nader-Grosbois, N. (2014). Self-perception, self-regulation, and metacognition in adolescents with intellectual disability. http://dx.doi.org/10.1016/j.ridd.2014.03.033

Nunnally, J. C. \& Bernstein, I, H. (1994). Psychometric Theory $3 r d$ Ed. USA: McGraw-Hill

OECD (2010), PISA 2009 Results: What Students Know and Can Do-Student Performance in Reading, Mathematics, and Science, (Volume I). http://dx.doi.org/10.1787/9789264091450-en

OECD. (2014). PISA 2012 Results in Focus: What 15-year-olds know and what they can do with what they know

Ozsoy, G., Memis, A., dan Temur,T. (2009). Metacognition, study habits and attitudes. International Electronic Journal of Elementary Education. Vol. 2, Issue 1

Perna, R. \& Loughan, A. R. (2014). The complexities of math skills development. International Journal of Mathematics, Game Theory, and Algebra, 23(3),165-185. Retrieved from https://search.proquest.com/docview/1711197191?accoun tid $=17242$

Sajadi, M., Amiripour, P., \& Rostamy-Malkhalifeh, M (2013). The examining mathematical word problems solving ability under efficient representation aspect. Mathematics 
Education Trends and Research. doi:10.5899/2013/metr00007

Seifi, M., Haghverdi, M., \& Azizmohamadi, F. (2012). Recognition of students' difficulties in solving mathematical word problems from the viewpoint of teachers. Journal of Basic and Applied Scientific Research. 2 (3). 2923- 2928

Soni, A. \& Kumari, S. (2017). The role of parental math anxiety and math attitude in their children's math achievement. International Journal of Science and Mathematics Education. DOI 10.1007/s10763-015-9687-5

Susanti, T. (2013). Sikap siswa terhadap matematika. Edumath.Vol.4. Retrieved from file:///D:/susanti\%202013\%20sikapthdp\%20math.pdf
Veenman, M. V. J., Wilhelm, P., \& Beishuizen, J. J.(2004). The relation between intellectual and metacognitive skills from a developmental perspective. Learning and Instruction. Doi:10.1016/j.learninstruc.2003.10.004

Vella, D. (2011). Students' attitudes towards Mathematics and its relationship to achievement gender and age. Thesis: University of Malta 